\section{SMOKING HABITS OF MONOZYGOTIC AND DIZYGOTIC TWINS}

\author{
BY
}

LARS FRIBERG, M.D.

LENNART KAIJ, M.D.

SVEN J. DENCKER, M.D.

AND

ERLAND JONSSON, Ph.D.

From the Institute of Hygiene, Karolinska Institute, Stockholm, the Psychiatric Department, University of Lund, and the Department of Puhlic Hygiene, the National Institute of Public Health, Stockholm

Various epidemiological investigations-for example, Doll and Hill (1954, 1956), and Hammond and Horn (1954)-have, independently of each other, demonstrated higher morbidity and mortality from, inter alia, cardiac disease and pulmonary cancer in tobacco smokers as compared with non-smokers. These findings have often been cited as evidence of a direct causal association between smoking and the diseases in question. The planning of the inquiries and the interpretation of results, however, have been sharply criticized from several quarters. For instance, it has been pointed out that in many respects smokers differ essentially from non-smokers, and for this reason comparison between the two groups is not entirely warrantable.

An important source of error in comparing smokers and non-smokers with respect to morbidity and mortality lies in the possibility of constitutional dissimilarities between the groups. It is thus conceivable that a common factor predisposes to the diseases as well as to excessive smoking. A study of a sufficient number of monozygotic twin pairs who differ in their smoking habits should substantially eliminate such sources of error and show the possibility of a causal connexion between smoking and disease.

Before an investigation of morbidity and mortality can be embarked upon, therefore, the smoking habits of twins must be charted. An inquiry of this type should also indicate the importance of the genotype in relation to smoking habits. If, for instance, it is found that twins of monozygotic pairs are more alike in smoking habits than twins of dizygotic pairs, the suggestion is that constitutional factors may significantly influence these habits.

\section{Present Investigations}

In all, 59 monozygotic and 59 dizygotic twin pairs were studied. These were taken from a series of 178 unselected twin pairs born at the obstetrical department of Lund University Hospital between 1900 and 1934 and described by Essen-Möller (1941). Essen-Möller divided this series into three groups. Group I comprised 43 pairs of monochorionic-true monozygotic-twins. Group III consisted of 73 pairs in which the blood groups differed according to the ABO and/or the MN system-definitely dizygotic twins. Group II contained the 62 remaining pairs: the twins of these pairs were apparently dichorionic, but were found to be alike with respect to the blood groupings employed, and thus constituted an uncertain group at the time of the original study.
By means of anthropological investigations by Essen-Möller (1941), supplemented by grouping of blood and serum-ABO, MNS, P, Duffy, Kell, Lewis, $\mathrm{Rh}$, and Lutheran blood group systems, the Gm serum group according to Grubb, and haptoglobin groups according to Smithies-group II could be divided into 19 monozygotic and 43 dizygotic twin pairs. In only one pair was there a reasonable doubt of zygosity. The general impression was that this pair was dizygotic; it was therefore counted as such. (Further details of the blood groupings will be published by M. Hauge, $L$. Kaij, and S. J. Dencker.)

The 59 pairs of monozygotic twins comprised 40 pairs from Essen-Möller's group I and all of the 19 monozygotic pairs from group II. Our 59 dizygotic twin pairs comprised all but 4 of the remaining pairs from group II and 20 from group III, selected so as to match the monozygotic group for age and sex. The distribution of the case material according to age and sex is shown in Table 1 .

\begin{tabular}{|c|c|c|c|c|c|c|}
\hline \multirow{2}{*}{ Zygosity } & \multicolumn{2}{|c|}{ No. of Pairs } & \multicolumn{4}{|c|}{ Year of Birth } \\
\hline & Malo & $\therefore$ emales & 1900-09 & 1910-19 & 1920-29 & $1930-34$ \\
\hline $\begin{array}{l}\text { Monozygotic } \\
\text { Dizygotic }\end{array}$ & $\begin{array}{l}21 \\
21\end{array}$ & $\begin{array}{l}38 \\
38\end{array}$ & $\begin{array}{l}6 \\
3\end{array}$ & $\begin{array}{l}7 \\
8\end{array}$ & $\begin{array}{l}26 \\
29\end{array}$ & $\begin{array}{l}20 \\
19\end{array}$ \\
\hline
\end{tabular}

Most of the twins were interviewed at personal visits from two of us (S. J. D. and L. K.). In a few cases the interview was conducted by telephone or, when this was not possible, by letter. A special questionary was used (important details of this are given in Appendix A).

The degree of concordance of smoking habits within the monozygotic and the dizygotic twin pairs was investigated by two methods.

1. The series was divided into four groups: regular smokers; sporadic smokers (less than one cigarette, cigarillo, or cigar a day) ; former smokers ; and other non-smokers. Chi-square analysis (see, for example, Siegel, 1956) was then used to compare the respective frequencies of concordance of this grouping within monozygotic and dizygotic twin pairs.

2. Forty "adjudicators" (public health officers, medical students, and a few laboratory assistants) received the following information of the twin pairs (see example in Appendix B): sex; age; qualitative smoking habits (regular or sporadic smoker, etc.) ; type of tobacco used (cigarettes, pipe tobacco, etc.) ; amount of tobacco used; changes in this amount; and age at which the subject began and ceased smoking. From this information, but without knowing whether the various pairs were monozygotic or dizygotic twins, the adjudicators estimated the degree of concordance in smoking habits according to an 11-degree scale, in which 11 denoted maximal and 1 minimal resemblance. The twin pairs were then ranked in accordance with the scale values, and the placing of the monozygotic and the dizygotic pairs was compared. This comparison was made with the Mann-Whitney $U$ test (see Siegel, 1956).

\section{Results}

Table II shows that the twins of monozygotic pairs belonged to the same group in 45 cases, whereas the corresponding figure among the dizygotic pairs was 
TABLB II.-Smoking Habits of the Twins ( $A=$ Regular Smokers, $B=$ Sporadic Smokers, $C=$ Former Smokers, $D=$ Other Nonsmokers)

\begin{tabular}{|c|c|c|c|c|c|c|c|c|c|}
\hline \multicolumn{5}{|c|}{ Monozygotic Pairs } & \multicolumn{5}{|c|}{ Dizygotic Pairs } \\
\hline \multirow{2}{*}{ Twin I } & \multicolumn{4}{|c|}{ Twin II } & \multirow{2}{*}{ Twin I } & \multicolumn{4}{|c|}{ Twin II } \\
\hline & A & B & C & D & & $\mathbf{A}$ & B & C & D \\
\hline $\begin{array}{l}\mathbf{A} \\
\mathbf{B} \\
\mathbf{C} \\
\mathbf{D}\end{array}$ & $\begin{array}{r}15 \\
3 \\
3 \\
4\end{array}$ & $\begin{array}{l}3 \\
0 \\
1\end{array}$ & $\frac{1}{3}$ & 26 & $\begin{array}{l}\mathbf{A} \\
\mathbf{B} \\
\mathbf{C} \\
\mathbf{D}\end{array}$ & $\begin{array}{r}15 \\
0 \\
7 \\
11\end{array}$ & $\begin{array}{l}0 \\
0 \\
2\end{array}$ & $\begin{array}{l}0 \\
5\end{array}$ & 19 \\
\hline
\end{tabular}

only 34. The chi-square analysis demonstrated a significantly greater proportion of concordant cases within the monozygotic group than within the dizygotic group $(0.01<\mathrm{P}<0.05)$.

Appendix $\mathrm{C}$ shows the rank number of each twin pair calculated from the median of the values given by the adjudicators. The sum for the monozygotic pairs was 3,076 and that for the dizygotic pairs 3,945 (in the rank-order the pairs with the highest median valuesscale values-were given the lowest numbers).

The Mann-Whitney $U$ test of the rank sums of both groups showed that the placing of the monozygotic pairs was significantly higher than that of the dizygotic pairs $(0.001<\mathrm{P}<0.01)$, which implies that concordance was greater within the monozygotic pairs. (The level of significance is not decreased even if pairs with rank numbers of 20.5 (see Appendix C) are excluded.)

\section{Discussion}

This investigation demonstrated greater concordance of smoking habits within monozygotic twin pairs than within dizygotic twin pairs. The difference was statistically significant concerning "qualitative" smoking habits as well as in estimations made from all data of smoking. Estimation of concordance may, of course, be made from other principles than those used in our study. It would seem, however, that the higher value in monozygotic twins will emerge in all appropriate methods. In our investigation we attributed special importance to the results based on appraisal by a large number of adjudicators who made their assessment on all the relevant data except zygosity.

How far may the results be said to indicate the importance of the genotype in relation to smoking habits ? According to the conventional interpretation they imply that smoking habits are definitely influenced by constitutional factors. In recent years, however, this interpretation of investigations on twins has to some extent been challenged by writers such as Bleuler (1955), who pointed out that the environment of monozygotic twins may be more uniform than that of dizygotic twins. If this is true it must be particularly prominent as a source of error concerning factors which $a$. priori can be classed as highly-susceptible to environment, such as smoking habits. On the other hand, one may object that, as a rule, smoking habits are formed after the twins have passed the years of maximum unity.*

*After this article was written our attention was drawn to a paper by R. A. Fisher (Nature (Lond.), 1958, 182, 596) in which he reports the smoking habits of 27 monozygotic twin pairs brought up apart. The concordance rate in this group was as high in a comparable but non-separated monozygotic group Althougb no detailed analysis is presented, this result contradicts the theory of mutual influence between the twins as a major cause of concorance and supports the view of genotropic influence on smoking habits.
To what extent our results may apply to other twin populations we have no certain knowledge. Quite independently of our inquiry, however, Fisher (1958) reported some preliminary observations in German twins. Although his material was not statistically analysed-possibly because the selection was not ideal-the tendencies in the results were identical with ours. It therefore seems probable that certain differences as regards smoking habits between monozygotic and dizygotic twin pairs are not confined to the fairly small population from which our material was collected.

Our investigation finally showed-and here, too, it received support from Fisher's findings-that in general a not insignificant proportion of monozygotic twin pairs may be expected to show discordance in regard to smoking habits. The feasibility of investigating the injurious effects of tobacco smoke from morbidity and mortality in twins will, of course, depend upon the number of twin pairs available. In this connexion, however, it should be pointed out that monozygotic twins who are concordant in smoking habits, and also dizygotic twins, constitute important groups for comparison. The number of discordant monozygotic twins, therefore, will not be the sole decisive factor.

\section{Summary}

A comparison between the smoking habits of 59 pairs of adult monozygotic twins and 59 pairs of adult dizygotic twins showed significantly greater concordance within the monozygotic pairs.

\section{APPENDIX A. PART OF THE QUESTIONARY Smoking Habits}

10. Do you smoke ?: No. Yes. Indefinite reply.

11. If " no" in point 10. Did you smoke formerly? No. Yes. Indefinite reply.

17. If yes or indefinite in point 10. What do you smoke? Cigarettes. Cigars or cigarillos. Pipe.

18. If yes or indefinite in point 10. Do you smoke daily or sporadically? Daily. Sporadically. Don't know.

19. If yes or indefinite in point 10 . How much do you smoke? Number of cigarettes per day. Number of cigars or cigarillos per day. A packet of tobacco $(50 \mathrm{~g}$.) lasts ...... days.

20. If yes or indefinite in point 10. How old were you when you began to smoke regularly ? .......years.

22. If yes or indefinite in point 10. Are you smoking more than you did five years ago? More. Less. The same. Don't know.

\section{APPENDIX B. EXAMPLES OF THE DATA FROM WHICH CONCORDANCE WAS ESTIMATED}

Code No.

Sex: Males.

Born : 1927

Twin A does not smoke now and has not smoked formerly.

Twin B does not smoke now and has not smoked formerly.

Code No.

Sex: Males.

Born : 1926

Twin A does not smoke now, but formerly smoked 10 cigarettes per day. He began to smoke when he was 14 years old and ceased when he was 32 .

Twin B smokes 15 cigarettes per day and sporadically smokes a pipe. He began to smoke when he was 15 years old and smokes less now than five years ago. 


\section{APPENDIX C. RANK NUMBERS OF THE TWIN PAIRS*}

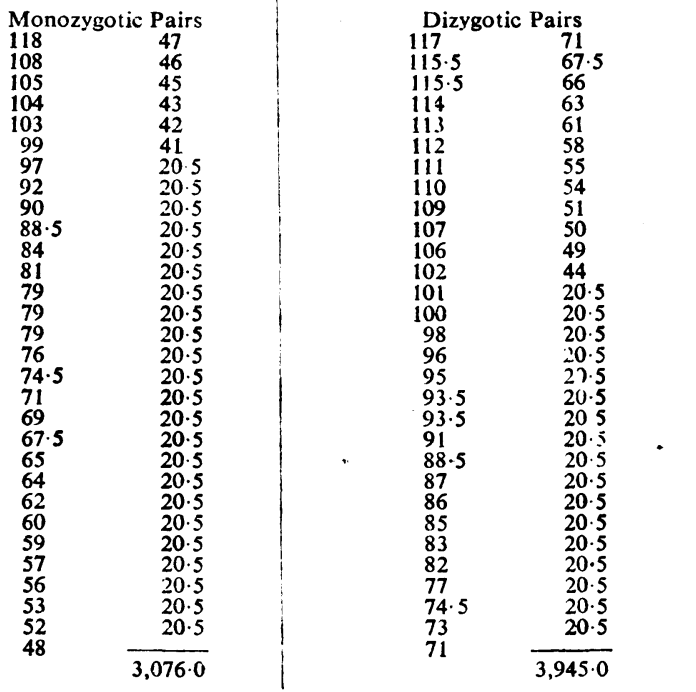

* Rank-order based on the results of appraisal of all data. Low number signifies strong concordance.

\section{REFERENCES}

Bleuler, M. (1955). Familial and Personal Background of Chronic Alcoholics: Etiology of Chronic Alcoholism, edited

by O. Diethelm, p. 110. Thomas, Springfield.

Doll, R., and Hill, A. B. (1954). Brit. med. J., 1, 1451.

- (1956). Ibid., 2, 1071

Essen-Möller, E. (1941). Hereditas (Lund), 27, 1.

Fisher, R. A. (1958). Nature (Lond.), 182, 108.

Hammond, E. C., and Horn, D. (1954). J. Amer. med. Ass., 155 1316.

Siegel, S. (1956) Nonparametric Statistics for the Behavioral Sciences. McGraw-Hill, New York.

\section{Medical Memoranda}

\section{A Case of Anaemic Gangrene of the Bowel}

Mesenteric vascular occlusion was first reported by Tiedman in 1843. From that time it was observed increasingly by Virchow, Moor, Hegar, and Chiene, until at the turn of the century Jackson, Porter, and Quinby, in America, were able to collect 214 cases. Leslie Trotter (1913) published an excellent and comprehensive monograph on the subject. He drew attention to a group of cases in which the intestines presented as a pale or " anaemic infarct" as distinct from the more commonly observed congested plum-coloured infarct. He quotes a series of nine cases. Eight were collected from the literature, the other was a case under the care of Sir Rickman Godlee reported by Trotter, who described the affected bowel as " white or yellowish grey in colour and entirely devoid of blood. At one or both ends of the infarcted segment there may be a demarcation zone of hyperaemia separating it from healthy intestine, as in the case of anaemic infarcts in other parts of the body. The wall of the affected coil is generally very thin."

\section{Case Report}

A woman aged 76 was admitted to the Royal Hospital, Wolverhampton, on September 20,1957, as a case of auricular fibrillation with severe abdominal pain of 22 hours' duration. Her general condition on admission was poor ; she was collapsed, with a barely perceptible pulse and a blood pressure of $60 / 40$. Her story, for she was quite lucid and mentally alert, was that one hour after her midday meal the previous day she was seized by severe central abdominal pain associated with some bilious vomiting. The pain gradually increased in severity, and after a restless night her general condition suddenly deteriorated, culminating in the collapsed state with which she presented in the casualty department.

Examination of the abdomen revealed a moderate degree of distension, with tenderness on the right spreading across the epigastrium. There was some guarding but no rigidity.

Bowel sounds were absent. There had been absolute constipation since the onset of pain. Rectal examination did not reveal any blood or abnormally coloured faeces.

A straight $x$-ray film did not reveal any fluid levels but showed a peculiar gas shadow below the liver on the extreme right. Serum amylase was within the limits of normal.

The patient responded to sedation and the administration of intravenous fluids. Her blood pressure rose to $120 / 80$ during the afternoon and stabilized at this level. At this point it was decided to perform a laparotomy.

Under general anaesthesia a laparotomy was performed through a paramedian incision. When the peritoneum was incised the odour of putrefaction arose. The intestines were bathed in a foul-smelling turbid fluid-not blood stainedand presented as a grey infarct with the proximal coil of jejunum plum-coloured, as were the terminal ilonm and colon.

As the patient's general condition began to doteriorate rapidly an emergency closure was done and she was returned to the ward. She died that evening.

At the post-mortem examination, carried out by Dr. A. G. Marshall, an embolus was found to have lodged in the superior mesenteric artery just below the inferior pancrenticoduodenal branch. Progression clot was present in all the branches of the artery below this point. The heart was hypertrophied and the left auricular appendage was full of old thrombus: one piece was lying loose in the auricle.

\section{COMMENT}

The cause of this type of gangrene is obscure, in that it is difficult to account for the absence of reflux of portal blood. Moore (1941) recognized this rare condition in a survey of mesenteric vascular occlusion but was unable to explain its occurrence. Klass (1951) and Van Weel (1953) reported cases in which embolectomy was performed and which would fit into this category of anaemic gangrene. These gave a history of 12 and 13 hours' duration.

The case reported here was of at least 27 hours' duration when brought to laparotomy, and at least 18 hours had elapsed before circulatory collapse occurred.

No reasonable cause was found on post-mortem examination to account for the lack of reflux of portal blood when relieved of its normal vis a tergo by the impact of the embolus in the superior mesenteric artery. .The portal vein and its tributaries were normal. The proximal jejunum and the caecum did, of course, show congestion of the more usual venous type.

I thank Mr. C. Vincent Patrick for his advice and permission to publish this case. Dr. A. G. Marshall kindly supplied the details of the post-mortem examination.

J. McKessar Duncan, F.R.C.S.,

Late Senior Registrar, Queen Elizabeth Hospital, Birminghan.

\section{BIBLIOGRAPHY}

Cokkinis, A. J. (1926). Mesenteric Vascular Occlusion. Bailitre Tindall and Cox, London.

Ficarra, B. J. (1944).' Amer. J. Surg., 66, 168.

Klass, A. A. (1951). Ann. Surg., 134, 913.

Moore, T. (1941). Brit. J. Surg., 28, 347.

Moore, T. (1941). Brit. J. Surg., 28, 347.

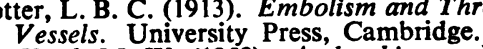

Van Weel, M. W. (1958). Arch. chir. neerl., 6, 149. 